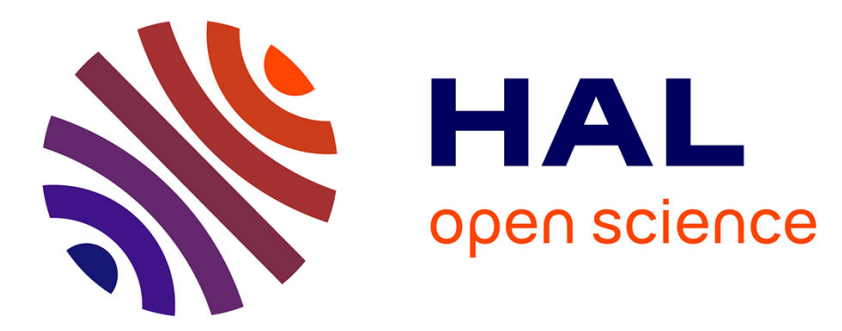

\title{
Research Investigation on Food Information User's Behaviour
}

\author{
Antonio Palmiro Volpentesta, Alberto Michele Felicetti
}

\section{To cite this version:}

Antonio Palmiro Volpentesta, Alberto Michele Felicetti. Research Investigation on Food Information User's Behaviour. 19th Working Conference on Virtual Enterprises (PRO-VE), Sep 2018, Cardiff, United Kingdom. pp.190-202, 10.1007/978-3-319-99127-6_17 . hal-02191179

\section{HAL Id: hal-02191179 \\ https://hal.inria.fr/hal-02191179}

Submitted on 24 Jul 2019

HAL is a multi-disciplinary open access archive for the deposit and dissemination of scientific research documents, whether they are published or not. The documents may come from teaching and research institutions in France or abroad, or from public or private research centers.
L'archive ouverte pluridisciplinaire HAL, est destinée au dépôt et à la diffusion de documents scientifiques de niveau recherche, publiés ou non, émanant des établissements d'enseignement et de recherche français ou étrangers, des laboratoires publics ou privés. 


\title{
Research Investigation on Food Information User's Behaviour
}

\author{
Antonio Palmiro Volpentesta, Alberto Michele Felicetti \\ ${ }^{1}$ Department of Mechanical Energy and Management Engineering, University of Calabria, \\ Via P.Bucci, 87036 Rende (CS), Italy \\ \{antonio.volpentesta, alberto.felicetti\}@unical.it
}

\begin{abstract}
Recent advances in smart food technologies have renewed the attractiveness of those studies on human information behaviour that take the food consumer as focus of interest. In this paper, we introduce a reference framework to model the food information usage process and the interrelation between the food consumer's behaviour and the food information user's behaviour. Basing on this framework, we present a literature review that classifies research works according to research approach types and stages of the food information usage process. The aim is to present a state of art of significance to food marketing and to the development of food intelligent services with higher satisfaction and value.
\end{abstract}

Keywords: food information, consumer's behaviour, information user's behaviour, literature review, intelligent food services

\section{Introduction}

The current paradigm shift towards a digital consumer society is leading new digital business to collect a big amount of food data that can be transferred and processed further with data analytics and intelligence tools. Food data are about food composition, consumer preferences, preparation and other food consumption activities (e.g., online recipes, databases of bio-molecular compounds in foods, restaurant reviews, and so on). Data management tools are based on crowdsourcing, data mining, large-scale data analysis, machine learning, and network analysis.

These trends with the continuous penetration of smart technologies are driving the emergence of intelligent food services that support food business in better understanding food consumers, improving marketing researches, and increasing food processes efficiency. For example, restaurant chains are investigating how big data can help to understand better the consumer behaviour inside a restaurant and to discover best practices to improve background processes. They look at big data analytics on menu entries and clusters of customers to optimize the drive-thru experience and to challenge spikes in demand ahead of time.

On the consumer's side, the availability of food information and intelligent services can give the food consumer new insights into his/her choice, propose novel ingredient combinations, and identify socio-cultural, safety, nutritional and bio-molecular factors that determine which foods we enjoy and why [1]. They are already changing food consumption activities as shaping food consumer culinary preferences, habits, and food 
information needs. Moreover, these services may shape new form of businesses based on platforms of collaborative food consumption.

This new context makes research studies on the relationship between the behaviours of food consumer and food information user quite important. Several studies addressed the role of food information in food consumption activities [2]. However, literature lacks of a holistic overview of the way food consumers behave in seeking, selecting and using food-related information. This paper intends to fill this gap providing a literature review of scientific research that combines knowledge on food consumer's and food information user's behaviours. Research topics are classified according to research approach types and stages of the food information usage process that is a series of consumer's food information related activities. Throughout this paper, rather than simply focusing on 'information use', in the narrowest sense of usage, we refer to it as the process that comprises all stages from the identification of a food information need through the final stage of information contextualization and use.

The aim is to present a state or art that identifies mature areas of research, areas requiring further investigation, and current and future research directions of significance for the development of new food information services with higher satisfaction and value.

\section{Background and Motivations}

Consumers are daily involved in food-related activities: planning what to eat, purchase, store and cook food, eating, and disposing remnants. The series of consumer's foodrelated activities is known as food provisioning [3] or food consumption process [4]. Over recent years, patterns of food consumption have experienced rapid change, as result of the growing interest of consumers on health, food safety, environmental and social issues. For that reason, food consumer behaviour is a widely addressed topic in scientific literature.

Consumer behaviour is defined as the set of activities directly involved in obtaining, consuming and disposing product, services or experiences, to satisfy needs and desires [5]. Basing mainly on cognitive approaches to consumer behaviour, specific behavioural models with respect to the food consumption process have been developed across the years. Such models are mainly based on social cognitive theory [6] and the theory of planned behaviour [7].

Information processing of marketing stimuli is central to explain consumer behaviour [8]. As matter of fact, information plays a crucial role in reducing uncertainty during a decision-making process [9]. Needs for information emerge from the recognition of a gap between a person's knowledge current state and his/her desirable state [10]. Due to its nature, an information need arises as an output of a more basic need. It is a part of the search for the satisfaction of a physiological, affective or cognitive need, as an individual is engaged on "information seeking towards the satisfaction of needs" [11]. Users' behaviour in information seeking and use is widely investigated under the concept of human information behaviour [12]. This literature stream attempts to develop generalizable explanations of human behaviour when 
humans acquire and process information, including selection, evaluation, and use of information contents, sources and channels [13].

Over recent years, the information behaviour of food consumers is assuming growing interest from many different perspectives (food business marketing, food information business, public food authorities, food consumers). However, from whatever perspective, the emerging request is to manage in more effective ways food information, and this can be done by leveraging on a deeper knowledge about food information user's behaviour. The main challenge of food information management is to deliver the information that enables consumers to make appropriate choices according to their own individual objectives, as they are involved in food consumption activities. Unfortunately, information asymmetry occurs all along the food chain, deeply affecting consumer decision behaviour(s) [14]. This is mainly due to the intrinsic nature of food sector, often exposed to unknown characteristics. Quality and safety issues about food are difficult to identify, and in the majority of cases recognizable only after their consumption. In fact, depending on the type of attribute, food is considered as an experience (some food attributes can be determined just after purchasing and consumption) or credence good (some food attributes that cannot be determined by consumer even after consumption) [15]. Main consequences of asymmetric information are moral hazard (a food producer takes more risks (e.g. falsely labelling, food adulteration) because consumers bear the burden of those risks, and adverse selection (producers hide some food information in a transaction, leading consumers to poor decisions making). Several scholars address the problem of asymmetries proposing solutions to overcome moral hazard and adverse selection, by means of contracts, product labelling and monitoring system (public or private), certifications [16]. However, conventional ways of food information provisioning seem not to solve the problem of asymmetries, justifying the increasing interest towards innovative solution for a more effective food information provision. On the one hand, consumers are demanding more and more relevant, reliable and appropriate food information for their decision-making. On the other hand, food information providers face the challenge of identifying what kind of food information consumers are interested in and when, where and how information should be provided [1]. Recent advances in "Internet of food" technologies (such as food sensors, cloud computing, food data analysis, and mobile app technologies) makes possible to conceive new food information services, letting consumers get more relevant food information than they usually obtain through on-product labeling, mass media or other traditional channels.

\section{Food Information Usage Process}

In what follows we present a reference framework to model the food information usage process and the interrelation between the food consumer's behaviour and the food information user's behaviour. Food needs are human primary needs that may come from internal stimuli, normally a physiological or emotional needs (e.g. hunger, desire for salty/sweet foods) or from external stimuli (e.g. an advertisement, the smell /the sight of yummy food, etc.). They let often arise food-related primary needs associated 
with a consumer's activity in a stage of the food consumption process (e.g. purchasing appropriate food products, choosing where to buy food, planning meals).

The identification of a food information need represents the first stage of the information usage process. It starts as soon as the consumer recognizes an aroused foodrelated primary need or a need to fill a knowledge gap. The food consumer becomes aware that food information should be acquired and collected in order to meet that need. $\mathrm{He} / \mathrm{she}$ translates a food-related need or the awareness of a food knowledge gap into an information question relevant to a choice in a specific food consumption stage or to a food learning activity. This leads the food consumer to become a food information user. The clarity of the information question is crucial for the success of the rest of the process, i.e. the retrieval and use of the desired food information.

Food information seeking is the second stage of the information usage process. In this stage, the food information user is actively and purposefully involved in a conscious effort to acquire information in response to a food-related need or a need to fill a food knowledge gap. From a decisional point of view, food information users have to choose the appropriate information channel and the information source able to meet his/her food information need. A user may explore several information channels (e.g. labels, social media, mobile apps) and information source (e.g. food producers, distributors or other food supply chain stakeholders) and ends his/her research when he/she evaluates the retrieved information as sufficiently relevant and reliable. Nowadays, collaborative food information seeking and sharing represent a recent aspect of food information consumer's behaviour. The increased availability of social media tools facilitates interactive communication among consumers, leaving a large margin for third parties to become food information providers (e.g., food bloggers, forum, recommender systems) [17]. In fact, social media make possible food consumers to group themselves in communities around a collective purpose and contribute to the production or dissemination of food information [18]. Beyond advantages deriving from collaborative food information seeking, some critical issues about the trustworthiness of the information provided are emerging in research studies [19].

The output of food information seeking is an information cue that a consumer could use to support his/her food decision-making or learning process.

Once food information is selected, consumers can use it for some food choices in a food-related activity, i.e. an activity of the food consumption process or an activity of a food learning process. How consumers interpret, give meaning to, evaluate, and use food information depends on their previous experience, expertise, and needs, as well as their current consumption context, i.e. situational and temporal conditions in which the consumer's food choice occurs [20]. Context awareness has a significant influence on the food information user, as context cues can support user to better interpret foodrelated information. In fact, context awareness provides the user with sensory and cognitive cues that allow him/her to refer delivered data and information to food items. An information content can be properly interpreted by taking into account other elements within the environment surrounding food products the information content is referring to, e.g. other food products, specific physical conditions (e.g. light, humidity, temperature, localization, spatial layout, package integrity) or organizational features (e.g. operation rules, shop opening). In other words, contextualization is necessary to the use of the food information for either to make an appropriate consumption choice or to enable a deliberate food learning process. 
Lastly, we recall that a food learning process can be also triggered by psychobiological stimuli when the consumer is directly involved in a food consumption activity. Trial-and-error approaches, social interactions, lessons learned carrying out real-life food activities, allow consumers to acquire knowledge to create or modify their ideas and values about food.

The above food information usage process and its interrelation with the food consumption process is presented in Figure 1.

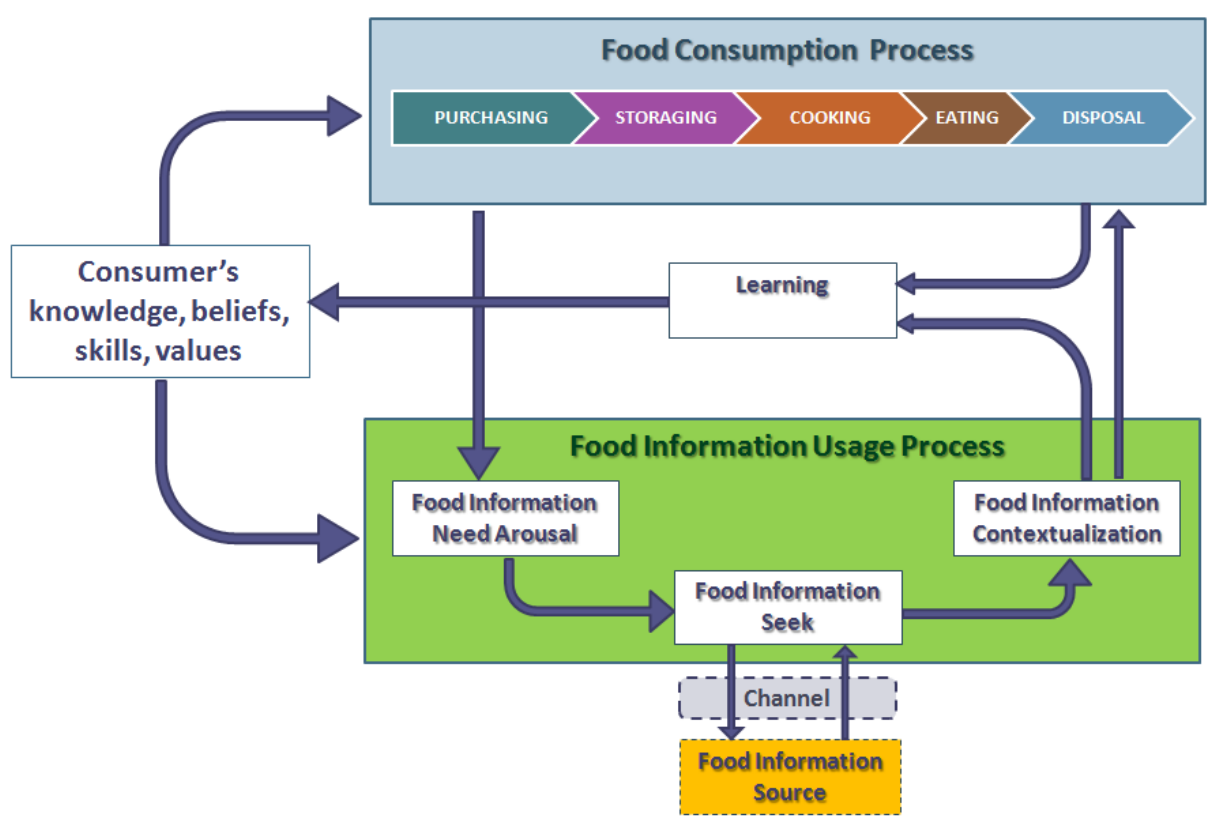

Fig. 1. The food information usage process and the interrelation between the food consumer's behaviour and the food information user's behaviour

\section{Literature Review}

In our work, we carried out a literature review of scientific papers on human information behaviour that take the food consumer as the focus of interest. In what follows, we present the methodology we have adopted and main results arising from the analysis of retrieved papers that are classified according to research approaches and stages of the food information usage process.

\subsection{Methodology}

We selected Google Scholar as scientific research engine where to perform our search We initialized a list L of search keywords with English terms related to the above 
mentioned scientific domain (e.g. "information seeking", "need for information", "information need arousal", "consumer behaviour", "information behaviour", as well as synonymous, and other broader/wider terms). We performed a search on Google Scholar using keywords in the list L coupled with term "food" and other terms used for major food groups. We identified main research lines in the domain of food consumer information behaviour. Moreover, the list $\mathrm{L}$ was possibly extended by adjoining new terms found among the author keywords of each paper. The activity was iteratively performed until no newer keywords or new papers were found. We analysed the abstract of each paper in order to determine whether it matched our inclusion criterion: the paper deals with a phase of the food information usage process at least.

At the end of this cycle, we obtained the final set $\mathrm{P}$, consisting of 64 papers to be analysed. For each paper $\mathrm{p} \in \mathrm{P}$ we identified the research line(s) addressed in that paper and the research approach(es) adopted. To classification purposes, we selected the following research approaches [21]: literature review, empirical research (quantitative survey, case study), model.

\subsection{Results}

For sake of clarity, we present our results in three subsections each of which corresponds to one of the main activities of food information usage process, namely food information needs identification, food information seeking and food information contextualization. The complete list of papers we reviewed is available at: https://drive.google.com/open?id=1NGNDkVRtusIcm_C6w6cBga2DAJQIHT8X

\subsubsection{Food Information Needs Identification}

Extant literature in cognitive psychology and behavioural economics attempts to explain the link between the rational consumer and necessary inputs, capabilities and willingness to engage in a food decision making process. A food information need arouses as a consequence of consumer's involvement in a food consumption activity, and it is affected by some consumer's attributes (interests, attitudes, experiences, and knowledge). In fact, food information needs vary from a consumer to another and may affected from the judgement of their values and beliefs, habits, the tools available for information search and the knowledge about these tools [P7]. Some authors identify consumer interests, motivational states and habits as drivers in food information needs arousal [P1]. However, we may summarize the general research questions in literature about the identification of food information needs as follows:

- Why do consumers need food information and what information do they need?

- What activates their food information need?

These questions have been tackled under either a specific perspective reflecting a consumer's interest in a food property type or a psychological perspective related to the antecedents of a consumer's interest. We have grouped food properties in 6 broad classes, namely healthiness, safety, convenience, hedonism, culture and ethics/sustainability which correspond to 6 specific perspectives:

Healthiness: this research direction addresses the impact of health-related consumers' values on food information user's needs. Researches are centred on the 
identification of consumer's interest towards health related food information, e.g. healthy food properties (e.g. anticancer) [P4], food wellness related properties (e.g. anti-ageing food, food improving skin elasticity) [P5], nutritional composition of the food (protein, carbs, fat, calories, vitamins, minerals) [P3]. Survey based research demonstrated that consumers with health related interests, have continuous and more intense information needs about food [P6][P12].

Safety: researches are devoted to investigate the way a consumer's information need arises under a safety-related perspective, They show that this arousal is strictly entwined with the consumer's perception of risks associated to food-related hazards [P8], e.g., chemical and microbiological contaminants associated with food chains [P9], presence of preservatives, colorants, and artificial sweeteners in food products [P10].

Convenience: researches are addressed to study food information need arousal in consumers whose main interest is towards food costs and convenience. They are mostly devoted to determine what consumer's information needs are from what they depend, e.g. buying food at a lower price, finding the nearest food store, and, more in general, gaining benefits during food related activities [P14].

Hedonism: few research works, explicitly focusing on the relationship between the pleasure of food and information need arousal, have been found in scientific literature. However, some of them give some considerations about consumers' information needs, although they restricted the attention to a specific food group, e.g. meat [P15]; others have been oriented to determine the terms that consumers use to indicate and measure emotions associated with foods [P16]. Of course, these results can be of some interest for further research on identifying food information needs of consumers, mainly driven by concern for sensory quality of food products. As matter of fact, they may help to understand how consumers conceptualize and express food information needs into words.

Culture: although cultural interests and patterns of consumer's behaviour towards food have been largely studied in literature, the impact of socio-cultural interests and dispositions towards the arousal of food information needs has been scarcely investigated. Some researchers have linked up these interests with food consumers (called foodies) who recognize their food information needs in a continuous commitment to self-education (learning about food typicity, traditions and values, trying new cooking techniques, reading magazines, cookbooks, culinary history, and food blogs) [P18].

Ethic/sustainability: researches have been focused on information needs of consumers that are driven by taking social and environmental concerns of food products into account, i.e. 'ethical consumerism'. They mainly investigate consumer's preferences and needs of information about 'fair trade' aspects (e.g., fair prices to farmers, integration of handicapped people, animal welfare, preservation of biodiversity) and other food-related sustainable practices from an environmental and social point of view (e.g., reduction of greenhouse gases, protection of the tropical rainforest, prevention of child labour) [P21].

The last perspective deals with the identification of psychological factors that influence individual consumer's need for information:

Psychological: researches in this direction are devoted to investigate individual characteristics that shape the arousal of food information needs. Some of them deals 
with variables in the psychological domain such as uncertainty, involvement, personality and knowledge [P22].

In table 1 we summarize results of our review, specifying the type of research approach and related references.

Table 1. Research directions on food information needs identification.

\begin{tabular}{|l|l|l|}
\hline \multicolumn{1}{|c|}{ Perspective } & \multicolumn{1}{|c|}{ Research Type } & \multicolumn{1}{c|}{ References } \\
\hline \multirow{5}{*}{ Healthiness } & Quantitative Survey & P1, P2, P3 \\
\cline { 2 - 3 } & Empirical Research & P4, P5 \\
\cline { 2 - 3 } & Qualitative Study & P6 \\
\hline \multirow{5}{*}{ Safety } & Review & P7 \\
\cline { 2 - 3 } & Quantitative Survey & P8, P9, P10, P11, P12 \\
\cline { 2 - 3 } & Model & P13 \\
\hline Convenience & Qualitative Study & P14 \\
\hline Hedonism/emotion & Model & P15, P16 \\
\hline Cultural & Quantitative Survey & P17, P18 \\
\cline { 2 - 3 } & Review & P19 \\
\cline { 2 - 3 } & Qualitative & P20 \\
\hline Ethical/sustainabilty & Quantitative Survey & P21 \\
\hline Psychological & Review & P22 \\
\hline
\end{tabular}

\subsubsection{Information Seeking}

Scholars identified several patterns in food information seeking, depending on whether food consumer perceives a real need for information [P22], his/her emotional state [P23] or his/her skills [P24]. From a decisional point of view, when a user is consciously involved in an effort to acquire information about food, he/she has to choose the appropriate information channel and the information source able to meet his/her food information need. Information channel refers to a medium used by the consumer in finding food information (mobile-apps, blogs, newspapers, radio stations, television stations, and so on). Information source refers to persons or organizations (public authorities, food firms, third parties food product certifiers, educational organizations, information practitioners and other food supply chain stakeholders) from which food information comes to consumers.

Research on food information seeking attempted to understand how users behave when they search for food information, including factors affecting the selection and the evaluation of information sources and channels. We summarize the general research questions about food information seeking process as follows:

- Which factors influence information channel selection in food information seeking?

- How do consumers use information channels to seek food information?

- Which determinants motivate consumers to choose a food information source?

With respect to the first question, extant literature has been concerned with consumer's perceived channel benefits as main factors influencing the selection of a food information channel. Researches have been conducted to identify benefits that are linked up to information channel availability and accessibility as well as to consumers' 
effort reduction. Benefits have been investigated for many internet and mobile-based channels that can overcome some limitations of traditional channels (e.g. labels, radio, and television), as making information retrievable whenever and wherever the consumer needs for (in time and in place information). Some researches provide empirical evidences about the impact of channel availability and accessibility on the consumer's channel selection [P25][P26][P27] as well as time and cognitive efforts required by information searching on a given channel [P28][P29][P30].

The second research question has garnered less attention in literature on food information user's behaviour. Some scholars have tackled this question by focusing on a restricted domain of food information, pertaining to some food quality attribute (e.g., safety), and new internet and mobile-based channels. They investigated consumers' intention to use current prevalent online and offline information channels. For instance, some of them investigated the inclination of consumers, who are familiar with social media applications, to use these as a channel to seek information about safety related $[\mathrm{P} 33][\mathrm{P} 34]$ or health related issues [P35], compared to other more traditional mass media and Internet channels.

With reference to the third research question, source credibility is widely recognized as the main determinant affecting consumer's choice of a food information source. Source credibility refers to the extent to which a recipient believes that the source has considerable knowledge, skills and experiences to provide objective information without bias. Credibility of food information sources includes several aspects influencing the extent to what individuals consider a source credible. Recently, some empirical studies have been carried out to identify factors that affect the credibility of a food information source. They mainly deal with three factors:

Perceived expertise: it refers to the degree to which recipients perceive the information source as having the experience, skills, and capacity to provide accurate information. Some researchers have given empirical evidences about perceived expertise and the impact on the overall evaluation of the information sources. For example, Van Dillen et al. [P42] ranked several information sources about health and nutrition according the degree of expertise perceived by Dutch consumers. Hiddink et al. [P43] investigated some sources of nutrition information and found that perceived expertise of noncommercial sources was much higher than for commercial sources.

Trustworthiness: it deals with the confidence that the source provides objective and correct information. Most of the research aimed to determine to what extent consumers trust in food information sources and which factors affect their trust in those sources [P45]. Several researches, based on survey approach, tend to segment consumers according to their level of trust with respect to information sources [P46]. Other researchers investigated determinants of source trustworthiness as mediating effect on eWOM credibility [P49].

Attractiveness: it refers to the degree to which an information source is appealing to consumers by exerting verbal, physical, or technology-mediated communication. Few research works, explicitly focusing on information source attractiveness, have been found in scientific literature. Some of them empirically investigated the influence of food blog attractiveness on blog user's trust in blog information [P53].

In table 2 we summarize results of our review, specifying the type of research approach and related references. 
Table 2. Research directions on food information seeking.

\begin{tabular}{|c|c|c|c|}
\hline Research Line & Focus & Research Type & References \\
\hline \multirow{3}{*}{$\begin{array}{l}\text { Factors influencing } \\
\text { food information } \\
\text { channel selection }\end{array}$} & \multirow[t]{3}{*}{ Channel benefits } & quantitative survey & $\begin{array}{l}\text { P25, P26, P27, P28, } \\
\text { P29, P30 }\end{array}$ \\
\hline & & model & P31 \\
\hline & & qualitative research & P32 \\
\hline $\begin{array}{l}\text { Consumers } \\
\text { motivation to use an } \\
\text { information channel }\end{array}$ & $\begin{array}{l}\text { Usefulness and } \\
\text { familiarity with } \\
\text { social media }\end{array}$ & quantitative survey & P33, P34, P35 \\
\hline \multirow{7}{*}{$\begin{array}{l}\text { Determinants in } \\
\text { consumer's choice of } \\
\text { a food information } \\
\text { source }\end{array}$} & \multirow[t]{3}{*}{ Perceived expertise } & qualitative research & P36 \\
\hline & & empirical research & P37, P38 \\
\hline & & quantitative survey & $\begin{array}{l}\text { P39, P40, P41, P42, } \\
\text { P43 }\end{array}$ \\
\hline & \multirow[t]{3}{*}{ Trustwhortiness } & quantitative survey & $\begin{array}{l}\text { P8, P44, P45, P46, } \\
\text { P47, P48, P49, }\end{array}$ \\
\hline & & qualitative research & P50, P51 \\
\hline & & review & P52 \\
\hline & Attractiveness & quantitative survey & P53 \\
\hline
\end{tabular}

\subsubsection{Information Contextualization and Use}

Food information use is widely investigated under a marketing perspective in terms of impact on consumer's behaviour, e.g. nutritional information influence on the decision to buy or not a food product. Of course, many information provider organizations (public authorities, food firms, and other food supply chain stakeholders), are interested in these investigations, as they tend to shape consumers' behaviour or to redirect their food-related decision-making. From the scientific literature's perspective, several studies have been conducted on the influence of food information on consumer choices in food consumption activities, but they rather limited their scope to some aspect of the information use process. Most of them have been focused on consumers' use of nutritional labels for purchasing decisions and dietary changes, see [P54] for a review, consumers' use of information about genetically modified food, or other safety related issues. However, we may summarize that they all face the following general research question about food information use:

- Which factors influence the information use in food consumer's choices?

Researches from the literature reveal that these factors pertain to the three main entities involved in food decision-making: consumer (who takes the decision), context (situational and temporal conditions in which the decision should be taken), and information (input of the decision-making process).

Consumer: pertaining factors refer to consumer's attributes that influence consumer's interpretation, evaluation, and use of a food information cue. They may be grouped in demographic characteristics (such as age, gender, education [P54]), motivation and interests (e.g. health-related interests [P55], food involvement [P56],), and food knowledge (e.g. ability to understand food information [P57]);

Context: extant research of information systems evidences that the way users give meaning and importance to information depends on temporal and location attributes of 
items within the context where users make decisions. Unfortunately, contextual factors have not been prioritized in previous research related to food information use. Few studies deal with the influence of context on food consumer decision making, focusing mainly on environmental factors [P58] and socio-cultural contextual factors [P11].

Information: few studies have been directed to empirically examine how much information use depends on the quality of the information a consumer receives. Some research works have focused on the influence of information content qualities, in terms of accuracy, currency, completeness, timeless, and understandability, on consumer's online food purchasing [P59]. Some others focused on consumer preferences about information content format or presentation attributes, but most of them limited their scope to investigate nutrition label formats [P54].

In table 3 we summarize results of our review, specifying the type of research approach and related references.

Table 3. Research directions on Food Information contextualization.

\begin{tabular}{|l|l|l|l|}
\hline \multicolumn{2}{|c|}{ Research Line } & \multicolumn{1}{c|}{ Research Type } & \multicolumn{1}{c|}{ References } \\
\hline $\begin{array}{l}\text { Factors } \\
\text { influencing the } \\
\text { information use } \\
\text { in food } \\
\text { consumer's } \\
\text { choices }\end{array}$ & Consumer & $\begin{array}{l}\text { Quantitative } \\
\text { survey }\end{array}$ & $\begin{array}{l}\text { P1, P63, P55, P56 } \\
\text { P60, P61, P62, P63, } \\
\text { P64, }\end{array}$ \\
\cline { 2 - 4 } & Context & $\begin{array}{l}\text { Quantitative } \\
\text { survey }\end{array}$ & P11, P53, P58 \\
\cline { 2 - 4 } & Information & $\begin{array}{l}\text { Quantitative } \\
\text { survey }\end{array}$ & P59 \\
\cline { 2 - 4 } & Review & P54 \\
\hline
\end{tabular}

\section{Conclusions and Future Research Directions}

Results arising from our literature review confirm a great interest that researchers have shown in food consumer's information behaviour over past decades. However, the identified research directions reflect a classical marketing perspective. The interrelation between the food consumer's behaviour and the food information user's behaviour has been investigated without taking into account current paradigms of Internet-of-Food and collaborative food consumption. Considering these new paradigms as part of the food consumption process, the food information usage process needs to be aligned and new research challenges need to be addressed in order to accelerate the development of the next generation of food information services with higher satisfaction and value.

In particular, capabilities of current context-sensitive technologies make urgent to open up research directions in order to investigate the role of food information contextualization in the food information usage process. As matter of fact, contextualization is absolutely essential both to let the consumer make appropriate choices in his/her food consumption activities and to enable consumer's informal learning process that is crucial for his/her future related behaviour. 


\section{References}

1. Volpentesta, A. P., Felicetti, A. M., Ammirato, S.: Intelligent Food Information Provision to Consumers in an Internet of Food Era. In Pro-VE 2017, 18th Working Conference on Virtual Enterprises, Springer (2017) 725-736.

2. Van Rijswijk, W., Frewer, L. J.: Consumer needs and requirements for food and ingredient traceability information. Int. J. of Consumer Studies, 36(3), 282-290, (2012).

3. Goody, J.: Cooking, cuisine and class. A study in contemporative sociology Cambridge University Press, Cambridge (1982).

4. Marshall, D.W.: Food choice, the consumer and food provisioning, D.W. Marshall (Ed.), Food choice and the consumer, Blackie Academic \& Professional, pp. 3-17, (1995).

5. Sirgy, M. J.: Self-concept in consumer behaviour: A critical review. Journal of consumer research, 9(3), 287-300, (1982).

6. Friese, M., Hofmann, W., Wänke, M.: When impulses take over: Moderated predictive validity of explicit and implicit attitude measures in predicting food choice and consumption behaviour. British Journal of Social Psychology, 47(3), 397-419 (2008).

7. Arvola, A., Vassallo, M., Dean, M., Lampila, P., Saba, A., Lähteenmäki, L., Shepherd, R.: Predicting intentions to purchase organic food: The role of affective and moral attitudes in the Theory of Planned Behaviour. Appetite, 50(2-3), 443-454 (2008).

8. Vermeir, I., Verbeke, W.: Sustainable food consumption among young adults in Belgium. Ecological economics, 64(3), 542-553 (2008).

9. Citroen, C. L.: The role of information in strategic decision-making. International Journal of Information Management, 31(6), 493-501 (2011).

10. Belkin, N. J., Oddy, R. N., Brooks, H. M.: ASK for information retrieval: Part I. Background and theory. Journal of Documentation, 38(2), 61-71, (1982).

11. Wilson, T. D.: On user studies and information needs. Journal of documentation, 62(6), 658670, (2006).

12. Spink, A., Cole, C.: Human information behaviour: Integrating diverse approaches and information use. J. of the Association for Inf. Science and Tech. 57(1), 25-35 (2006).

13. Browne, G. J., Cheung, C. M., Heinzl, A., Riedl, R.: Human Information Behaviour. Business \& Information Systems Engineering, 59(1), 1-2 (2017).

14. Starbird, S. A., Amanor-Boadu, V.: Contract selectivity, food safety, and traceability. Journal of Agricultural \& Food Industrial Organization, 5(1) (2007).

15. Grunert, K. G.: Current issues in the understanding of consumer food choice. Trends in Food Science \& Technology, 13(8), 275-285 (2002).

16. Hobbs, J. E.: Information asymmetry and the role of traceability systems. Agribusiness, 20(4), 397-415 (2004).

17. Corvello, V., Felicetti, A. M.: Factors affecting the utilization of knowledge acquired by researchers from scientific social networks: An empirical analysis. Knowledge management: An international journal, 13(3), 15-26 (2014).

18. Rutsaert, P., Pieniak, Z., Regan, Á., McConnon, Á., Kuttschreuter, M., Lores, M., Verbeke, W.: Social media as a useful tool in food risk and benefit communication? A strategic orientation approach. Food Policy, 46, 84-93 (2014).

19. Gao, Q., Tian, Y., Tu, M.: Exploring factors influencing Chinese user's perceived credibility of health and safety information on Weibo. Computers in human behaviour, 45, 21-31 (2015).

20. Booth, D. A.: Food-conditioned Eating Preferences and Aversions with Interceptive Elements. Annals of the New York Academy of Sciences, 443(1), 22-41 (1985).

21. Volpentesta, A. P., Felicetti, A. M.: Competence mapping through analysing research papers of a scientific community. In Doctoral Conference on Computing, Electrical and Industrial Systems, Springer, Berlin, Heidelberg (2011) 33-44. 